\title{
Kualitas Hidup ODHA Di Kecamatan Bongas
}

\author{
Wenny Nugrahati Carsita1, Mirah Asmi Kusmiran² \\ ${ }_{1}$ STIKes Indramayu, \\ email:wennynugraha16@gmail.com \\ 2Puskesmas Bongas
}

\section{Abstract}

HIV / AIDS is a chronic disease that can affect all aspects of a person's life. Bongas is a sub-district with the highest number of cases compared to other sub-districts in Indramayu Regency. HIV / AIDS is reported to not only cause symptoms and complications but also has a negative impact on quality of life. Quality of life will affect the health condition of people living with HIV, especially in treatment programs. The aim of this study was to determine the quality of life of PLWHA in Bongas. This study used a quantitative research with descriptive approach. The sample amounted to 165 respondents with taking consecutive sampling technique. The results of the study were 118 (71.5\%) respondents had a good quality of life in physical domain, 84 (50.9\%) respondents had a good quality of life in psychological domain, 124 (75.2\%) respondents had a good quality of life in social domain, 93 (56.4\%) had a good quality of life in the independence domain, 86 (52.1\%) respondents had a good quality of life in the environmental domain, and 86 (52.1\%) respondents had a good quality of life in the spiritual domain. The conclusion of this study is that PLWHA in Bongas have a good quality of life.

Keywords: Quality of Life, PLWHA 


\section{Abstrak}

HIV/AIDS merupakan penyakit kronis yang dapat berdampak pada semua aspek kehidupan penderitanya. Bongas merupakan kecamatan dengan jumlah kasus tertinggi dibandingkan dengan kecamatan lain di Kabupaten Indramayu. Penyakit HIV/AIDS dilaporkan bukan hanya menimbulkan gejala dan komplikasi melainkan juga memiliki dampak negatif pada kualitas hidup. Kualitas hidup akan mempengaruhi kondisi kesehatan ODHA terutama dalam program pengobatan. Penelitian ini bertujuan untuk mengetahui kualitas hidup ODHA di Kecamatan Bongas. Jenis penelitian ini kuantitatif dengan pendekatan deskriptif. Sampel penelitian berjumlah 165 responden dengan teknik pengambilan consecutive sampling. Hasil penelitian sebanyak $118 \quad(71,5 \%)$ responden memiliki kualitas hidup domain fisik baik, 84 (50,9\%) responden memiliki kualitas hidup domain psikologis baik, 124 (75,2\%) responden memiliki kualitas hidup domain sosial baik, $93(56,4 \%)$ memiliki kualitas hidup domain kemandirian baik, 86(52,1\%) responden memiliki kualitas hidup domain lingkungan baik, dan $86(52,1 \%)$ responden memiliki kualitas hidup domain spiritual baik. Simpulan pada penelitian ini adalah ODHA di Kecamatan Bongas memiliki kualitas hidup baik.

Kata kunci: Kualitas Hidup, ODHA 
Pendahuluan

HIV/AIDS

merupakan

kronis yang dapat berdampak pada semua aspek kehidupan

penderitanya

(Bunjoungmanee, et al., 2014). Sejak pertama kali ditemukan, HIV/AIDS telah menjadi salah satu masalah

kesehatan utama di dunia (Liping, et al., 2015). Sampai dengan tahun 2018, ada lebih dari 37,9 juta orang hidup dengan HIV dan 770.000 orang meninggal karena AIDS (UNAIDS, 2018).

Di Indonesia, pada tahun 2016 kasus HIV dilaporkan mencapai 41.250 kasus. Pada tahun 2016 kasus AIDS dilaporkan sedikit meningkat dibandingkan tahun 2015 yaitu sebanyak 7.491. Secara kumulatif, kasus AIDS sampai dengan tahun 2016 sebesar 86.780 kasus (Kementrian Kesehatan RI, 2017).

Penyakit HIV/AIDS dilaporkan bukan hanya menimbulkan gejala dan komplikasi melainkan juga memiliki dampak negatif pada kualitas hidup penderitanya (Mbada, et al., 2013). Liping et al. (2015) mengungkapkan

HIV/AIDS sebagai penyakit kronis selain menimbulkan efek samping dari penggunaan obat dan infeksi oportunistik, juga dapat memungkinkan

penderitanya mengalami stigma dan diskriminasi. Hal tersebut tentu akan mempengaruhi

kesejahteraan

ODHA secara keseluruhan baik fisik, psikologis, sosial dan ekonomi. Oleh karena itu, program pengobatan yang diberikan bukan hanya untuk memperpanjang umur ODHA melainkan juga untuk meningkatkan kualitas hidupnya

(Bunjoungmanee, et al., 2014).

Kualitas

merupakan

hidup penting untuk menilai 
dampak dan kualitas dari suatu

perawatan (Bunjoungmanee, et al., 2014). World Health Organization mendefinisikan (WHO) hidup sebagai persepsi individu mengenai posisinya dalam kehidupan, budaya, dan nilai yang berkaitan dengan tujuan, harapan yang mencakup beberapa aspek yaitu fisik psikologis, kemandirian, tingkat hubungan serta (Medeiros, et al., 2017). Cella dan Bonomi (1995) mendefinisikan kualitas hidup sebagai sejauh mana kesehatan fisik, emosi, dan sosial seseorang dipengaruhi oleh kondisi medis atau perawatannya (Chua \& Han, 2014).

\section{Indramayu}

merupakan Kabupaten dengan jumlah kasus AIDS terbanyak ketiga dan kasus HIV terbanyak keempat di Jawa Barat (Dinas Kesehatan Provinsi Jawa Barat, 2016). Di Kabupaten Indramayu sampai bulan
Juni tahun 2017 tercatat sebanyak 2.737 kasus HIV, dan sebanyak 1.572 kasus AIDS. Bongas merupakan kecamatan dengan jumlah kasus HIV/AIDS tertinggi dibandingkan dengan kecamatan lain di Kabupaten Indramayu, di mana hingga bulan Juni tahun 2017 tercatat sebanyak 281 kasus (Dinas

Kesehatan Kabupaten Indramayu, 2017).

Basavaraj et al. (2010) mengungkapkan setelah terinfeksi HIV, ODHA dilaporkan sulit beraktivitas, tidak cukup memiliki energi, serta sering mengalami kelelahan. Selain itu, ODHA juga melakukan penghindaran seperti penarikan sosial, menggunakan alkhohol untuk mengatasi stress, bahkan menggunakan narkoba.

Kualitas hidup yang buruk akan mempengaruhi kondisi ODHA. Kualitas hidup diyakini mempengaruhi tingkat kepatuhan ODHA 
dalam mengkonsumsi ARV. ODHA dengan kualitas hidup yang baik memiliki kemampuan yang lebih besar untuk mematuhi pengobatan, mengatasi penyakit, dan mengelola kehidupannya (Oguntibeju, 2012; Liping et al., 2015).

Berdasarkan hasil studi pendahuluan yang dilakukan pada 7 ODHA diperoleh bahwa setelah terinfeksi HIV, ODHA merasa tidak berdaya, cemas dan putus asa. ODHA juga mengeluh cepat merasa leleh, demam, sakit kepala, berat badan turun, kulit gatal, sariawan pada mulut dan diare. Adanya penurunan kondisi fisik tersebut mempengaruhi pekerjaan dan aktivitas ODHA. Namun demikian, dalam pemenuhan kebutuhan sehari-hari ODHA melakukan mandiri.

mengatakan mampu secara ODHA bersyukur ada keluarga yang selalu mendukungnya. Disisi lain, 2 mengatakan bahwa yang mengetahui status penyakitnya petugas hanya Keduanya tidak mau keluarganya mengetahui status penyakitnya dikarenakan khawatir mendapatkan penolakan. Penelitian ini bertujuan untuk mengetahui kualitas hidup ODHA di Kecamatan Bongas.

\section{Metode Penelitian}

Penelitian

ini

menggunakan desain kuantitatif dengan pendekatan deskriptif. Sampel dalam penelitian ini merupakan ODHA dengan stadium 2-3, berusia 15-60 tahun, dapat membaca dan menulis, dan bersedia menjadi responden yaitu sebanyak 165 responden. Teknik pengambilan sampel menggunakan consecutive sampling. Instrumen yang digunakan mengadopsi kuesioner WHOQOL-HIV BREF. 


\section{Wenny Nugrahati Carsita: Hidup ODHA}

\section{Hasil Penelitian}

1. Karakteristik Responden

a. Umur

Tabel. 1

Karakteristik Responden

Berdasarkan Umur $(\mathrm{N}=165)$

\begin{tabular}{ccccccc}
\hline \multirow{2}{*}{$\mathbf{N}$} & mean & median & sd & $\begin{array}{c}\text { min- } \\
\text { max }\end{array}$ & $\begin{array}{c}\mathbf{9 5 \%} \\
\mathbf{C I}\end{array}$ \\
\hline umur & 165 & 33.42 & 32.00 & 8.752 & $\begin{array}{c}15- \\
58\end{array}$ & $\begin{array}{c}32.08- \\
34.78\end{array}$ \\
\hline
\end{tabular}

Berdasarkan tabel. 1 diketahui rata-rata umur responden adalah 33 tahun dengan umur tertua adalah 58 tahun dan umur termuda adalah 15 tahun.

b. Jenis Kelamin, Tingkat Pendidikan, Pekerjaan, Faktor Resiko dan Stadium.

\begin{tabular}{|c|c|c|c|}
\hline $\begin{array}{c}\text { Karakteristik } \\
\text { Responden }\end{array}$ & Katagori & $\begin{array}{c}\text { Frekuensi } \\
\text { (F) }\end{array}$ & $\begin{array}{c}\text { Presentase } \\
(\%)\end{array}$ \\
\hline \multirow{2}{*}{ Jenis Kelamin } & Laki-laki & 34 & 20,6 \\
\hline & Perempuan & 131 & 79,4 \\
\hline Total & & 165 & 100.0 \\
\hline \multirow{5}{*}{ Pendidikan } & Tidak & 5 & 3,0 \\
\hline & Sekolah & & \\
\hline & SD & 126 & 76,4 \\
\hline & SMP & 31 & 18,8 \\
\hline & SMA & 3 & 1,8 \\
\hline Total & & 165 & 100.0 \\
\hline \multirow{6}{*}{ Pekerjaan } & IRT & 104 & 63,0 \\
\hline & K.Swasta & 1 & 0,6 \\
\hline & Lain-lain & 9 & 5,5 \\
\hline & Petani/Buruh & 26 & 15,8 \\
\hline & T.Bekerja & 3 & 1,8 \\
\hline & WPS & 22 & 13,3 \\
\hline Total & & 165 & 100.0 \\
\hline \multirow{5}{*}{ Faktor Resiko } & Lain-lain & 37 & 22,4 \\
\hline & LSL & 6 & 3,6 \\
\hline & Pelanggan & 20 & 12,2 \\
\hline & Waria & 2 & 1,2 \\
\hline & WPS & 100 & 60,6 \\
\hline Total & & 165 & 100.0 \\
\hline \multirow{2}{*}{ Stadium } & 2 & 100 & 60,6 \\
\hline & 3 & 65 & 39,4 \\
\hline Total & & 165 & 100.0 \\
\hline
\end{tabular}

Tabel.2Karakteristik Responden Berdasarkan Jenis Kelamin, Tingkat Pendidikan, Pekerjaan, Faktor Resiko, dan Stadium $(\mathrm{N}=165)$ 
Berdasarkan tabel. 2 diketahui sebanyak 131 $(79,4 \%)$ responden berjenis kelamin perempuan, $126(76,4 \%)$ responden berpendidikan SD, 104 (63\%) bekerja sebagai ibu rumah tangga, 100 $(60,6 \%)$ memiliki faktor resiko wanita pekerja seks (WPS), dan 100 $(60,6 \%)$ berada pada stadium 2.

c. Lama Menderita
dan Lama
Pengobatan

Tabel. 3

Karakteristik Responden Berdasarkan Lama Menderita dan Lama Pengobatan $(\mathrm{N}=165)$

\begin{tabular}{ccccccc}
\hline $\begin{array}{c}\text { Karakteristik } \\
\text { Responden }\end{array}$ & n & Mean & $\begin{array}{c}\text { Medi } \\
\text { an }\end{array}$ & SD & $\begin{array}{c}\text { (Min- } \\
\text { Max) }\end{array}$ & $\begin{array}{c}\text { 95\% } \\
\text { CI }\end{array}$ \\
\hline Lama & 16 & 3.13 & 3.00 & 1.697 & $1-8$ & $\begin{array}{c}2.87- \\
\text { Menderita }\end{array}$ \\
5 & & & & & 3.39 \\
\hline Lama & 16 & 3.14 & 3.00 & 1.742 & $1-8$ & $2.87-$ \\
Pengobatan & 5 & & & & & 3.41 \\
\hline
\end{tabular}

Berdasarkan tabel. 3 diketahui bahwa ratarata lama menderita dan rata-rata lama pengobatan adalah 3 tahun dengan minimum 1 tahun dan maximum 8 tahun.
2. Kualitas ODHA

Tabel. 4

Kualitas Hidup ODHA Di

Kecamatan Bongas

$(\mathrm{N}=165)$

\begin{tabular}{ccc}
\hline Katagori & $\begin{array}{c}\text { Frekuensi } \\
(\mathbf{F})\end{array}$ & $\begin{array}{c}\text { Presentase } \\
(\mathbf{\%})\end{array}$ \\
\hline Baik & 95 & $57,6 \%$ \\
Kurang & 70 & $42,4 \%$ \\
Baik & & \\
\hline Total & 165 & 100.0 \\
\hline
\end{tabular}

Berdasarkan tabel.

4 diketahui bahwa 95 $(57,6 \%)$ responden memiliki kualitas hidup baik dan 70 $(42,4 \%) \quad$ memiliki kualitas hidup kurang baik.

Tabel. 5

Kualitas Hidup ODHA

Berdasarkan Domain

Fisik, psikologis, Sosial, Kemandirian, Lingkungan, dan Spiritual $(\mathrm{N}=165)$

Domain Katagori Frekuensi Presenta 3.39 3.41
Fisik

Baik
(F)

118 se $(\%)$

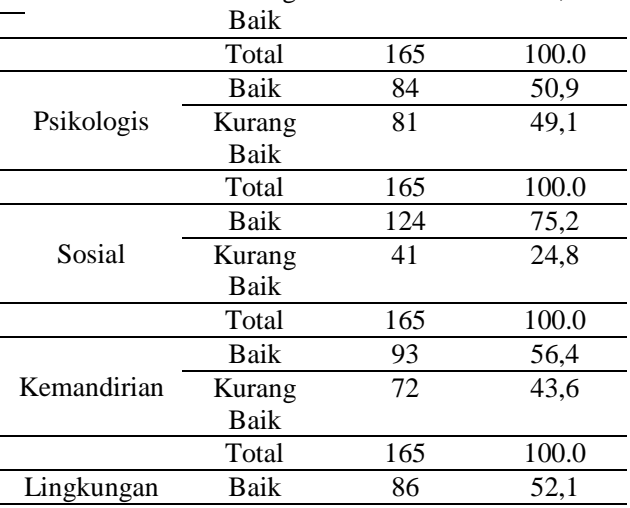




\begin{tabular}{cccc} 
& $\begin{array}{c}\text { Kurang } \\
\text { Baik }\end{array}$ & 79 & 47,9 \\
\hline & Total & 165 & 100.0 \\
\hline \multirow{3}{*}{ Spiritual } & Baik & 86 & 52,1 \\
\cline { 2 - 4 } & $\begin{array}{c}\text { Kurang } \\
\text { Baik }\end{array}$ & 79 & 47,9 \\
\hline & Total & 165 & 100.0 \\
\hline
\end{tabular}

Berdasarkan

tabel. 5 diketahui bahwa sebanyak 118 $(71,5 \%) \quad$ responden memiliki kualitas hidup domain fisik baik, $84(50,9 \%)$ responden memiliki kualitas hidup domain psikologis baik, $124(75,2 \%)$ responden memiliki kualitas hidup domain sosial baik, 93 $(56,4 \%) \quad$ memiliki kualitas hidup domain kemandirian baik, $86(52,1 \%) \quad$ responden memiliki kualitas hidup domain lingkungan baik, dan 86 (52,1\%) responden memiliki kualitas hidup domain spiritual baik.

\section{Pembahasan}

Kualitas

penting

hidup

mengevaluasi perawatan ODHA, efek samping penyakit, serta kesejahteraan ODHA (Folasire, et al., 2012;
Bello \& Bello, 2013). Hasil penelitian didapatkan $95 \quad(57,6 \%)$ ODHA memiliki kualitas hidup baik dan 70 $(42,4 \%) \quad$ memiliki kualitas hidup kurang baik.

Pada domain fisik, diketahui sebanyak 118 $(71,5 \%)$ ODHA memiliki kualitas hidup baik sedangkan domain kemandirian sebanyak 93 (56,4\%) responden memiliki kualitas hidup yang baik pula. Hal tersebut sesuai dengan karakteristik responden bahwa rata-rata usia ODHA tergolong dalam usia produktif yaitu 33 tahun. Usia produktif memungkinkan ODHA secara fisik masih kuat, masih bisa bekerja, berkarya, dan mampu melakukan aktivitas sehari hari secara mandiri. Selain itu, $60,6 \%$ ODHA dalam penelitian ini berada pada stadium II di mana pada stadium ini merupakan fase dengan gejala ringan. 


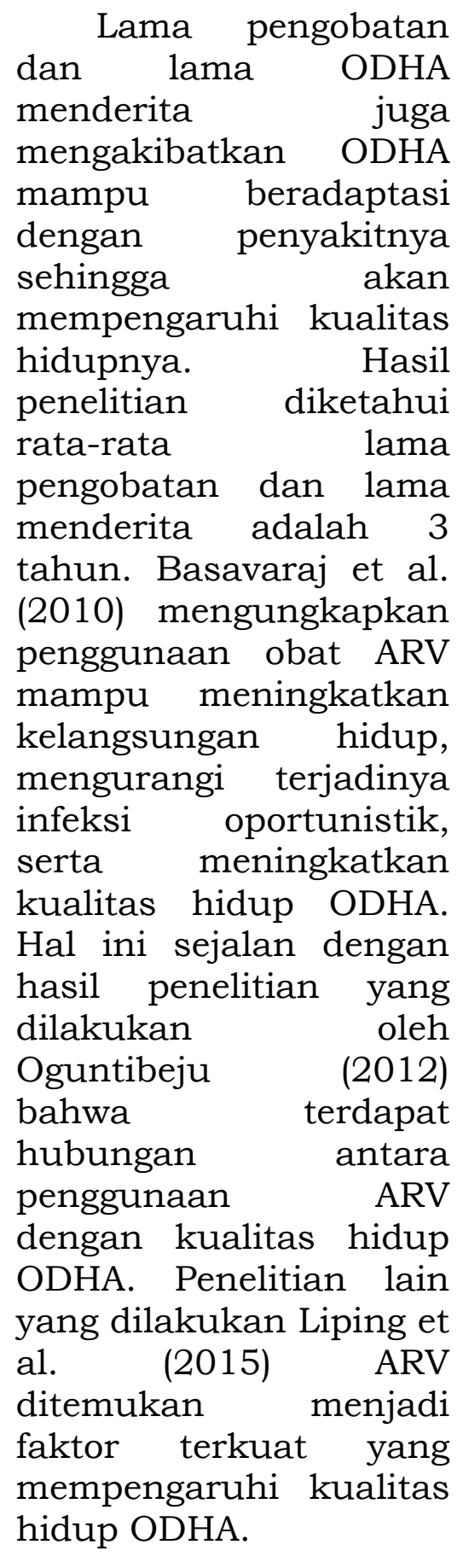

Novianti,

dkk. (2015) mengungkapkan bahwa pada stadium awal terinfeksi ODHA rentan mengalami stress. Beberapa penelitian mengenai aspek psikososial menunjukkan bahwa penyakit HIV/AIDS dikaitkan dengan masalah stress dan depresi. Hal tersebut berkaitan dengan koping yang digunakan ODHA untuk beradaptasi dengan stressor. Individu yang menghadapi stres dengan pendekatan pemecahan masalah dan modifikasi perilaku memiliki kualitas hidup yang jauh lebih baik daripada mereka yang tidak menggunakan keterampilan koping tersebut (Basavaraj et al., 2010). Rata-rata lama menderita pada ODHA yaitu 3 tahun memungkinkan ODHA akan terbiasa dan beradaptasi dengan penyakit yang diderita. $\mathrm{Hal}$ ini menunjukkan bahwa semakin lama 
ODHA

menderita

HIV/AIDS maka ODHA akan memiliki koping yang adaptif.

Hasil penelitian

menunjukkan bahwa sebanyak $84 \quad(50,9 \%)$ ODHA memiliki kualitas hidup domain psikologis baik. Hal tersebut diketahui bahwa ODHA tidak merasa cemas dengan kondisi yang dialami, tidak khawatir dengan kematian, serta tidak takut dengan masa depan meskipun menderita HIV/AIDS. Hal ini juga berkaitan dengan hasil penelitian yang menunjukkan bahwa pada domain sosial sebanyak 93 (56,4\%) ODHA memiliki kualitas hidup yang baik. Adanya dukungan dari orang terdekat seperti pasangan, keluarga telah terbukti memainkan peran penting dalam meningkatkan koping, harga diri, dan keterlibatan dalam menjalankan perawatan (Bunjoungmanee et al., 2014).
Khumsaen et al. (2012) mengungkapkan adanya hubungan yang positif antara dukungan sosial dengan kualitas hidup. ODHA yang memiliki kualitas hidup yang tinggi merasa bahwa dirinya lebih didukung dan menganggap bahwa kelurga merupakan sumber utama untuk dukungan secara fisik maupun psikologis. Hal ini juga berkaitan dengan hasil penelitian yang menunjukkan bahwa sebanyak 86 $(52,1 \%) \quad$ responden memiliki kualitas hidup domain lingkungan baik. Tidak adanya tekanan dari lingkungan yang dirasakan akan membuat ODHA merasa aman dan cenderung patuh untuk menjalankan pengobatan.

Hasil penelitian diketahui bahwa 86 (52,1\%) responden memiliki kualitas hidup domain spiritual baik. Spiritualitas merupakan faktor penting untuk 
perasaan kesejahteraan. Spiritualitas dianggap sebagai jembatan antara keputusasaan dengan kebermaknaan hidup sehingga erat kaitannya dengan kesejahteraan psikologis (Basavaraj, 2010). Hasil penelitian menunjukkan bahwa pada domain psikologis ODHA memiliki kualitas hidup yang baik pula.

\section{Simpulan}

Kualitas

hidup

ODHA di Kecamatan Bongas berdasarkan domain fisik, psikologis, sosial, kemandirian, lingkungan, dan spiritual adalah baik. Namun demikian, pada beberapa domain juga ditemukan masih tingginya responden yang memiliki kualitas hidup yang kurang baik. Oleh karena itu, melalui penelitian ini diharapkan tenaga kesehatan dapat mengetahui menyadari pentingnya memperhatikan seluruh aspek pada penanganan pasien HIV / AIDS melalui

konseling kunjungan sebagai pemberian dukungan agar ODHA mampu mempertahankan pengobatan dan meningkatkan kualitas hidup.

\section{Daftar Pustaka}

Basavaraj, K. H., Navya, M. A., and Rashmi, R. 2010. Quality of life in HIV/AIDS. Indian Journal of Sexually

Transmitted

Diseases and AIDS, 31(2):75-80. doi: 10.4103/02537184.74971 .

Bello, S.I., and Bello, I.K. 2013. Quality of life of HIV/AIDS patients in a secondary health care facility. Proceedings Baylor University Medical Center, 26(2): 116119.

Bunjoungmanee, P., Chunloy, K., Tangsathapornpong A., 
Khawcharoenporn, T., and Apisarnthanarak, A. 2014. Quality of life assessment among patients living with $\mathrm{HIV} / \mathrm{AIDS}$ at a tertiary hospital care

Thailand. in

Southeast Asian Journal of Tropical Medicine and Public Health, 45(4): 834842.

Chua, S.P., and Han, T.J. 2014.

Characteristics and quality of life among people living with HIV at drop-in centres and shelter homes in Malaysia. Disability, CBR and Inclusive

Development Journal, 25(3): 6477. doi

10.5463/DCID.v25i 3.379 .

Dinas Kesehatan

Kabupaten

Indramayu. 2017. Jumlah Kasus HIV/AIDS Di Indramayu.
Dinas

Kesehatan

Provinsi Jawa

Barat. 2016. Profil Kesehatan Provinsi Jawa Barat Tahun 2016.

http: / /www.depkes .go.id/resources/do wnload/profil/PRO FIL_KES_PROVINSI _2016/12_Jabar_20 16.pdf.

Folasire, O.F., Irabor, A.E., and Folasire, A.M. 2012. Quality of life of People living with HIV and AIDS attending the Antiretroviral

Clinic, University College Hospital, Nigeria. Afr J Prm Health Care Fam Med, 4(1): 8 pages. http://

dx.doi.org/ 10.4102

/phcfm. v4i1.294.

Kementrian Kesehatan RI. 2017. Profil Kesehatan

Indonesia Tahun 2016. Jakarta:

Kementerian Kesehatan RI.

Khumsaen, N., Aouppor, W., and Thammachak, P. 
Wenny Nugrahati Carsita: Hidup ODHA

2012. Factors influencing quality of life among people living with HIV (PLWH) in

Suphanburi

Province, Thailand. Journal of the Association of Nurses in AIDS Care, 23: 63-72. doi:10.1016/j.jana. 2011.01 .003$.

Liping, M., Peng, X., Haijiang, L., Lahong, J., and Fan. L. 2015. Quality of Life of People Living with HIV/AIDS: A CrossSectional Study in Zhejiang Province, China. PLoS One, 10(8): $\quad 1-14$. doi: $10.1371 /$ journ al.pone.0135705

Mbada, C.E., Onayemi, O., Ogunmoyole, Y., Johnson, O.E., and Akosile, C.O. 2013. Health-related quality of life and physical functioning in people living with HIV/AIDS:

a case-control design. Health and
Quality of Life Outcomes, 11:106. Medeiros, R.C.D.S.C., Medeiros, J.A, Silva, T.A.L.D., Andrade, R.D., Medeiros, D.C., Araújo, J.S, Oliveira, A.M.G., Costa, M.A.A., and Dantas, P.M.S. 2017. Quality of life, socioeconomic and clinical factors, and physical exercise in persons living with HIV / AIDS. Rev Saude Publica, 51(66): 1-7. doi: 10.1590/S15188787.20170510062 66.

Novianti, S.D., Parjo., dan Dewi, A.P. 2015, Faktor-faktor yang mempengaruhi kualitas hidup penderita HIV yang menjalani rawat jalan di Care Support and Treatment (CST) Rumah Sakit Jiwa Daerah Sungai Bangkong kota 
Wenny Nugrahati Carsita: Hidup ODHA

Pontianak. Proners Jurnal

Keperawatan. 3 (1) Oguntibeju, O.O. 2012.

Quality of life of people living with HIV and AIDS and antiretroviral

therapy. HIV/AIDS Research and

Palliative Care, 4:117-124. doi: $10.2147 /$ hiv.s3232 1.

United

Nations

Programme on HIV/AIDS. 2016. AIDS By The Number. Geneva. https://www.unaid s.org/en.

Kholisotin. (2017). The Effectiveness Of Preclampsia Educational Package To The Knowledge, Attitude, And Skill Of Pregnant Women At Risk Of Preeclampsia.

Universitas Muhammadiyah Jakarta.

Munir, Z. (2017). Analisis pengaruh Pendidikan, Pendapatan dan Pekerjaan terhadap Motivasi Orangtua dalam

Kualitas

Perawatan Anak dengan

HIV/AIDS. Universitas

Muhammadiyah Jakarta.

Munir, Z., \& Romadhoni, F. (2019). PENGARUH PENDIDIKAN DAN PEKERJAAN

ORANGTUA DENGAN TINGKAT

KEPATUHAN ARV PADA ANAK HIV / AIDS. Jurnal Ilmiah STIKES Citra Delima Bangka Belitung, 2, 131135. 